\title{
Desigualdades Socioeconômicas nas Condições de Saúde da População Idosa da Região Sudeste do Brasil
}

\author{
Natália Martins Arruda (IC - Bolsista PIBIC/CNPq) e Prof ${ }^{a}$ Dra Luciana Correia Alves (Orientadora), \\ Departamento de Demografia-IFCH, UNICAMP.
}

\section{Resumo}

Em uma época em que a população idosa aumenta em relação a população total e os indivíduos passam a viver mais, aumenta o interesse em investigar como são vividos esses anos adicionais na expectativa de vida. Este estudo analisa as desigualdades nas condições de saúde dos idosos da região sudeste do Brasil. As análises baseiam-se em dados do suplemento de saúde da Pesquisa Nacional por Amostra de Domicilio do IBGE, de 1998, 2003 e 2008. Os resultados destacam a existência de importantes diferenças nas condições de saúde dos idosos de rendas mais baixas e mais altas e dos de maior e menor escolaridade.

Palavras- Chave: Desigualdades socioeconômicas, expectativa de vida saudável, doenças crônicas, saúde do idoso.

\section{Introdução}

O Brasil experimenta um intenso processo de envelhecimento e aumento da longevidade da população. Além disso, o país está entre aqueles com graus mais elevados de desigualdade social no mundo. A situação socioeconômica desempenha um papel fundamental na determinação da saúde dos indivíduos. As doenças crônicas são consideradas as maiores causas de mortalidade, constituindo um importante problema de saúde da população em todo o mundo, especialmente entre os idosos. A expectativa de vida saudável é uma medida que combina informações de morbidade e mortalidade em um único índice. Sendo assim, o objetivo do presente estudo foi mensurar, para os idosos da região sudeste brasileira, por sexo, educação, renda e raça/cor da pele, a expectativa de vida livre de e com hipertensão, diabetes, bronquite/asma, doença do coração nos anos de 1998, 2003 e 2008.

\section{Resultados e Discussão}

Entre os homens idosos o número de anos a serem vividos livres de doenças crônicas é maior entre aqueles que se encontram com renda $20 \%$ mais alta. Em 1998, os mais ricos esperavam viver dos 15,5 anos restantes de vida, 14,7 anos livre de doenças respiratórias. Por sua vez os mais pobres 13,9 anos. Ainda em relação a renda, os resultados mostraram o impacto das desigualdades de sexo no acesso a saúde, ou seja, em termos relativos, as mulheres podem esperar viver em média menos tempo restante de vida livre de hipertensão comparativamente aos homens. Quanto à escolaridade, os idosos com escolaridades mais altas (12 anos ou mais de estudo) vivem em média um ano a mais livre de hipertensão em relação aos de escolaridade mais baixa (0 a 4 anos de estudo). No grupo etário de 60-64 anos, as mulheres de educação mais alta esperavam viver livre de diabetes 17,1 anos em relação a 15,1 anos das de escolaridade mais baixa. Indivíduos com mais escolaridade têm maior acesso aos cuidados de saúde e às medidas preventivas (Noronha \&Viegas, 2002). No que se refere a cor da pele, as maiores diferenças encontradas estão na hipertensão. Os indivíduos de cor branca tendem a viver 1 ano a mais livre da doença se comparado aos de cor não branca.

\section{Conclusões}

Ações integradas em políticas públicas para reduzir as desigualdades socioeconômicas entre os idosos são elementos chaves para se alcançar um envelhecimento ativo, contribuindo para que os anos adicionais de vida sejam desfrutados com qualidade e bem-estar.

\section{Agradecimentos}

Os autores agradecem ao apoio financeiro do CNPq.

\footnotetext{
1 Lima-Costa MF, Facchini LA, Matos DL, Macinko J. Mudanças em dez anos das desigualdades sociais em saúde dos idosos brasileiros 91998-2008). Rev Saúde Pública 2012; 46:100-107.

${ }_{2}$ Noronha KVMS, Andrade MV. Desigualdades sociais em saúde e na utilização dos serviços de saúde entre os idosos na América Latina. Rev Panam Salud Publica. 2005;17(5/6):410-8.
} 